\title{
An Examination Of Bahamian Respondents' Task And Relationship Orientations: Do Males Have A Significantly Different Score Than Females?
}

Bahaudin G. Mujtaba, Nova Southeastern University, USA

\begin{abstract}
Leaders get things done through building relationships and getting tasks done in a timely manner. The focus on leadership of people in different cultures are of great importance to managers since they want tasks done in a timely manner and healthy relationships maintained with their vendors and customers. To explore the orientation of respondents in the Bahamas, this research focused on the differences of male and female Bahamian respondents. From the responses of 211 individuals in Nassau, it appears that Bahamians have significantly different scores on the relationship and task orientations. They are more relationship-oriented. The responses of 46 males and 165 females demonstrate significant differences based on gender. The information is useful for international managers and expatriates working in the Bahamas. Suggestions for future research and implications are presented.
\end{abstract}

Key words: Relationship orientation, task orientation, leadership, culture, and the Bahamas.

\section{INTRODUCTION AND CULTURAL VALUES}

$\mathscr{\mathcal { F }}$ or managers and business leaders, especially when working in a new cultural environment such as the Bahamas, understanding behaviors of their customers and employees is even more important for the organization's success. Therefore, it is important for researchers and educators to reflect on the leadership orientation of people in different cultures and examine how differences in context can lead to cultural misunderstanding between employees and customers (Huang and Mujtaba, 2009). The purpose of this research is to analyze the relationship similarities and dissimilarities between male and female Bahamian respondents. It is assumed that due to their socialization, Bahamians will score higher on the relationship orientation since they are considered to be collective and high context culture.

Dutch cultural anthropologist, Geert Hofstede, defines culture as the collective programming of the mind which differentiates the members of one human group or category from those of another in a given society (Hofstede, 1983, 1993). Societal and organizational cultural norms are learned through acculturation and socialization as they are not transmitted biologically from one person to the next. A society's culture is generally passed on through socialization with family, educational institutions, community activities, workplace relationships, etc. (Tajaddini \& Mujtaba, 2009; Mujtaba \& Balboa, 2009). Cultures are generally shared by individuals from the same society or organization. One of the factors that make a culture different from others is also what makes communication difficult between diverse people groups. Unfortunately, cultural misunderstandings, which are usually associated with miscommunication, stereotypes and lack of relevant knowledge, often lead to discriminatory practices (Walters Balfour and Mujtaba, 2009; Kaifi \& Mujtaba, 2009). As explained by Kaifi and Mujtaba (2010), transformational leaders tend to use their higher levels of emotional intelligence to rise above stereotypes through effective interpersonal skills. Of course, good interpersonal skills are highly dependent on effective communication skills. Understanding of culture and groups of people can lead to better communication, and effective communication can greatly reduce conflict and undue stress among colleagues and employees in the workplace (Mujtaba and McCartney, 2010). 
According to Hofstede (1993), Trompannar (1992) and other researchers, cultures are the building block of different people groups. Cultures tend to impact and influence human behavior, thereby making it more predictable. People of a specific culture tend to have their common methods and codes of effective communication. Of course, effective communication is an essential skill both in business and in life. In international business it is important to realize that cultural differences severely affect the communication process. According to anthropologist Edward Hall, there is a clear distinction in the way of communicating between the high-context and low-context cultures (Mujtaba, 2007). In high-context cultures such as the Bahamas, Thailand, Japan, or India, there is a less verbally detailed communication and less written/formal information. There is a more subliminal understanding of what is communicated. Often what is left unsaid is as important as what is said. Low context cultures such as the United States, Australia or United Kingdom put more emphasis on the written or spoken words. In such an environment, communication is very explicit and clear, and normally "what is meant is what is said."

For international managers and expatriate employees, it is essential to understand the culture of the country or region in which it is doing business (Karadjova-Stoev \& Mujtaba, 2009). It is almost impossible for a manager or a company to be successful in a foreign country without relevant knowledge and understanding of the culture (Mujtaba \& Balboa, 2009). Managers of international operations should be aware of the importance of context in various countries. According to Mujtaba and Balboa (2009), context indicates the level in which communication occurs outside of verbal discussion which can impact the effectiveness of various leadership styles. Understanding the effect of the differences in context provides a knowledge base and cultural intelligence that can help provide not only strong teams but more over effective business relationships with a firm's vendors and customers in the region.

\section{THE BAHAMIAN CULTURE AND HETEROGENEITY}

The Bahamian culture embodies the characteristics of a modern society while revealing itself through its historical norms and mores. The country of Bahamas, made up of over 700 islands, is a very close neighbor to the United States. The United States and the Bahamas cooperate closely as the Island is a vacation destination to thousands of Americans and international travelers each year. For many organizations and employees, the friendly culture and work climate make the Bahamas a viable country for development, investment, retirement, and fun. As the slogan states, many perceive that "It's better in the Bahamas."

Bahamas is often seen as the "playground" of the "rich and famous," since during some months it has the highest concentration of wealth and celebrity in the world (Cavico and Mujtaba, 2008). The Bahamas is the leading Caribbean tourist destination, at least for most from the United States, which generates about $50 \%$ of the gross domestic product (GDP). It is estimated that the tourism industry, directly or indirectly, employs about 60,000 people which is roughly half of the total workforce and about fifteen percent of the total population.

The Government of the Bahamas welcomes foreign investment in tourism and banking, and has declared an interest in agricultural and industrial investments to generate local employment, particularly in white-collar or skilled jobs (Cavico and Mujtaba, 2008). Similar to most other countries, the Bahamian government tends to protect Bahamian business and labor interests in order to employ more of their citizens. The Bahamians tend to be collectivistic and know many of the families living near them since it is a very small country. In the Bahamian culture the group is still the primary unit of social organization as a consequence of their living in extended families; thus, this explains why it is easier for them to work cohesively as teams and groups.

Bahamians enjoy great political stability and freedom to elect leaders of their choice. The populated cities for business are Nassau and Freeport where people of different countries reside to do work with people from across the globe. Besides a well developed infrastructure, the Bahamas offers a rich culture. This research focuses on the leadership orientation of Bahamians to determine whether they are leaning more toward tasks or relationships.

\section{STUDY METHODOLOGY: TASK AND RELATIONSHIP ORIENTATIONS}

Focusing on the task and relationship orientations of employees and managers are important aspects of leadership and success in diverse cultures. Leadership is the process of influencing one's customers, employees and 
colleagues through the use of task and relationship behaviors (Kaifi and Mujtaba, 2010). Task behavior is about telling others what to do, as well as when, where, and how to do them; and relationship behavior is about providing socio-emotional support. Peter G. Northouse (2010) provides a useful instrument, known as Style Questionnaire, which can be used to obtain a general profile of a person's leadership behaviors regarding task and relationship orientations. The Style Questionnaire can be completed by oneself as well as one's friends, peers, bosses, and/or employees for comparison purposes. The results can show one's use of various task and relationship behaviors. To determine one's personal leadership characteristics, the person circles one of the options that best describe how he or she sees himself or herself (or the person that is being evaluated) regarding each statement. For each statement, the person indicates the degree to which he or she (or the person being evaluated) engages in the stated behavior. A rating of 1 means "Never" and a rating of 5 means "Always" with the person demonstrating the specific behavior. To determine one's scores for the leadership styles questionnaire, one can add the responses for the odd numbered items to determine the score for task-orientation behaviors, and add the responses for the even numbered items to determine the score for relationship-orientation behaviors. The scoring interpretation for the Style Questionnaire by Northouse (2010) is presented in Table 1.

Table 1 - Task and Relationship Score Interpretations

\begin{tabular}{lll}
\hline SCORES & DESCRIPTIONS \\
- $45-50$ & Very high range \\
- & $40-44$ & High range \\
$\bullet$ & $35-39$ & Moderately high range \\
- & $30-34$ & Moderately low range \\
- & $25-29$ & Low range \\
$\bullet$ & $10-24$ & Very low range
\end{tabular}

High task behavior scores tend to mean that the leader engages in more top-down communication by explaining what the follower is to do, as well as when, where, and how each function is to be accomplished (Mujtaba \& Balboa, 2009). High relationship behavior scores mean the leader engages in more joint communication with followers while providing socio-emotional support. Of course, the degree to which one engages in more task or relationship oriented behaviors should depend on the variables present in the situation; some of the situational variables can include the difficulty of the task, the importance of the job, the time available to get it done, and the readiness of the follower to successfully complete the task without much input. Effective leaders stay in control by managing through a balance of both task and relationship oriented behaviors, as appropriate, to make sure the objectives and goals are accomplished.

The research question for this study was to determine whether Bahamian respondents have a higher relationship orientation or task orientation. Another aspect of this study was to determine whether females have a higher or lower average scores on the relationship orientation or task orientation when compared with their female counterparts. The specific hypotheses for this study are as follows:

Null Hypothesis1: Bahamian respondents will have similar scores for relationship orientations and task orientations.

Null Hypothesis2: Bahamian female respondents will have similar scores for relationship orientations and task orientations.

Null Hypothesis3: Bahamian male respondents will have similar scores for relationship orientations and task orientations.

Null Hypothesis4: Bahamian male and female respondents will have similar scores on task orientations.

Null Hypothesis5: Bahamian male and female respondents will have similar scores on relationship orientations. 
For the purpose of this study, a copy of the questionnaire was physically submitted to 400 Bahamians living in Nassau and other Islands around it in the Bahamas. Of the total surveys distributed, only 230 were sent back to the researcher and 19 was not used since 6 were foreigners and 13 of the questionnaires were incomplete. A total of 211 completed responses, making up 165 females and 46 males, were used for analysis in this study. The population of females the Bahamas is higher than males, which explains the smaller responses from men. These Bahamian respondents were a convenient sample including colleagues, students, as well as their friends and family members.

\section{TASK AND RELATIONSHIP RESULTS}

The average scores of Bahamian respondents for task orientation falls in "moderately high range," and their relationship orientation average falls in "high range," as presented in Table 2. The trend for male and females also fall in the same general pattern with significant differences.

Table 2 - Orientation Scores of Bahamian Respondents

\begin{tabular}{|l|c|c|c|}
\hline $\begin{array}{c}\text { Bahamians } \\
\text { Respondents }\end{array}$ & No. & Average Task Orientation Score & $\begin{array}{c}\text { Average Relationship Orientation } \\
\text { Scores }\end{array}$ \\
\hline Females & 165 & 37.66 & 41.89 \\
\hline Males & 46 & 36.91 & 41.74 \\
\hline Total & 211 & 37.5 & 41.86 \\
\hline
\end{tabular}

As can be seen from Table 3 and using the t-test for differences in two means, at a 0.05 level of significance, the first null hypothesis ("Bahamian respondents will have similar scores for relationship orientations and task orientations") is rejected because the calculated t value (-6.8) falls outside the critical value of t for statistical significance; in other words, since the $t$ value does not fall within the critical values $(+1.96$ and -1.96$)$, the hypothesis cannot be supported. Furthermore, since the p-value $(\mathrm{p}<0.0001)$ is less than alpha $(\alpha)=0.05$, there is sufficient evidence to reject the null hypothesis.

Table 3- Bahamian Task vs. Relationship Orientations

\begin{tabular}{|l|c|}
\hline Task Orientation & 211 \\
\hline Sample Size & 37.5 \\
\hline Sample Mean & 7.31 \\
\hline Sample Standard Deviation & 211 \\
\hline Relationship Orientation & 41.86 \\
\hline Sample Size & 5.74 \\
\hline Sample Mean & -6.81 \\
\hline Sample Standard Deviation & $0.000(3 \mathrm{E}-11)$ \\
\hline$t$-Test Statistic & \\
\hline$p$-Value & \\
\hline
\end{tabular}

Based on the results, the task orientation and relationship orientation scores of Bahamian respondents appear to be significantly different. As such, one can conclude that the Bahamian respondents have dissimilar scores on the task and relationship orientations. Perhaps because of their culture and socialization, Bahamian respondents seem to be putting more emphasis on their relationships.

As can be seen from Table 4, the null hypothesis ("Bahamian female respondents will have similar scores for relationship orientations and task orientations") is rejected because $\mathrm{t}=-5.63$ does not fall within the critical value of +1.97 and -1.97 . Also, because the $p$-value $(p<0.0001)$ is smaller than alpha $(\alpha)=0.05$, there is sufficient evidence to reject the null hypothesis. Based on these results, female Bahamian respondents' scores are different on the task and relationship orientations. 
Table 4- Bahamian Females Task vs. Relationship

\begin{tabular}{|l|c|}
\hline Task Orientation & 165 \\
\hline Sample Size & 37.66 \\
\hline Sample Mean & 7.62 \\
\hline Sample Standard Deviation & 165 \\
\hline Relationship Orientation & 41.89 \\
\hline Sample Size & 5.92 \\
\hline Sample Mean & -5.63 \\
\hline Sample Standard Deviation & $0.00(4 \mathrm{E}-08)$ \\
\hline$t$-Test Statistic & \\
\hline$p$-Value & \\
\hline
\end{tabular}

As can be seen from Table 5 and using the t-test for differences in two means, at a 0.05 level of significance, the null hypothesis ("Bahamian male respondents will have similar scores for relationship orientations and task orientations") is rejected because $\mathrm{t}=-4.196$ does not fall within the critical values and the $\mathrm{p}$-value ( $<<$ 0.0001 ) is less than 0.05. Based on these results, it can be concluded that male Bahamian respondents have different scores on the relationship and task orientations.

Table 5- Bahamian Males Task vs. Relationship

\begin{tabular}{|l|c|}
\hline Task Orientation & \multicolumn{2}{|c|}{48} \\
\hline Sample Size & 36.91 \\
\hline Sample Mean & 6.13 \\
\hline Sample Standard Deviation & 48 \\
\hline Relationship Orientation & 41.74 \\
\hline Sample Size & 5.1 \\
\hline Sample Mean & -4.196 \\
\hline Sample Standard Deviation & $0.00(6.15 \mathrm{E}-05)$ \\
\hline$t$-Test Statistic & \\
\hline$p$-Value & \\
\hline
\end{tabular}

As can be seen from Table 6, the null hypothesis ("Bahamian male and female respondents will have similar scores on relationship orientations") is supported because the calculated t of -0.16 is within the critical values of $t$ for statistical significance (1.97 to -1.97$)$ and the p-value (0.87) is larger than alpha (0.05). Based on these results, the relationship orientation scores of male and female Bahamian respondents appear to be similar. Therefore, the hypothesis is accepted.

Table 6 - Bahamian Males/Females- Relationship

\begin{tabular}{|l|c|}
\hline Relationship Orientation - Males & \multicolumn{2}{|c|}{48} \\
\hline Sample Size & 41.74 \\
\hline Sample Mean & 5.1 \\
\hline Sample Standard Deviation & 165 \\
\hline Relationship Orientation - Females & 41.89 \\
\hline Sample Size & 5.92 \\
\hline Sample Mean & -0.159 \\
\hline Sample Standard Deviation & 0.87 \\
\hline$t$-Test Statistic & \multicolumn{2}{|c|}{} \\
\hline$p$-Value & \multicolumn{2}{|c|}{} \\
\hline
\end{tabular}

As can be seen from Table 7, the null hypothesis ("Bahamian male and female respondents will have similar scores on task orientations") is supported because the calculated t of -0.62 is within the critical value of t for statistical significance, and the p-value (0.53) is greater than alpha (0.05). Based on these results, the relationship orientation scores of male and female Bahamian respondents appear to be similar. Therefore, the hypothesis is accepted. 
Table 7- Bahamian Males/Females - Task

\begin{tabular}{|l|l|}
\hline Task Orientation-Males & 48 \\
\hline Sample Size & 36.91 \\
\hline Sample Mean & 6.13 \\
\hline Sample Standard Deviation & \multicolumn{2}{|l|}{} \\
\hline Task Orientation - Females & 165 \\
\hline Sample Size & 37.66 \\
\hline Sample Mean & 7.62 \\
\hline Sample Standard Deviation & -0.625 \\
\hline$t$-Test Statistic & 0.53 \\
\hline$p$-Value & \multicolumn{2}{|l|}{} \\
\hline
\end{tabular}

It was hypothesized that Bahamian respondents will have similar relationship and task orientations, and the current study did not support this hypothesis since their orientations appear to be significantly different as they are more relationship oriented. However, when compared with each other, male and female Bahamian respondents did have similar scores for relationship and task orientations.

\section{IMPLICATIONS AND LIMITATIONS}

This research has shown that Bahamian respondents are more relationship-orientated. Bahamians, due to their collectivistic nature and higher scores on relationship orientation, will share knowledge with their colleagues. As explained by Kaweevisultrakul, Mujtaba and Puriveth (2009), knowledge sharing is a critical component of effective leadership and success in the modern and competitive workplace. The orientation toward having and maintaining a strong relationship with one's peers and customers can make knowledge transfer and training a little more effective through group settings. International managers and expatriates working in Nassau should feel comfortable in knowing that Bahamian employees will work hard to maintain a healthy relationship with their colleagues, peers, customers, and superiors. The average scores of Bahamian respondents for task orientation falls in "moderately high range," and their relationship orientation average falls in "high range." Males and females in the Bahamas seem to have similar patterns in their leadership orientation regarding tasks and relationships.

There are some limitations to this study and the small number of male responses is one of them. Future can studies can duplicate the research with more male responses from the Bahamian population. Another limitation is the fact that this study was conducted with a general population in the Bahamas. Future studies can compare specific working populations with similar working backgrounds and demographic variables.

Although the survey in this study was distributed to both genders, yet it was only handed to employees and managers in the private sector in the Bahamas; a limitation that can be alleviated by extending the study to encompass employees of different segments of the private as well as the public sectors in the Bahamas. Moreover, the research can be broadened to include part-time employees in addition to full-time employees as well as individuals from variety of backgrounds which are abundant in the Bahamas.

Finally, future studies should compare those who have five or more years of management experience with those who have never been a manager to see if this is a variable in the task and relationship orientation scores of respondents.

\section{CONCLUSION}

This paper discussed some of the common differences regarding the Bahamian culture to compare the scores of male and female respondents on the task and relationship orientations. The Bahamians seem to have a significantly higher score on the relationship orientation. After reflecting on the behaviors of people in the Bahamas one is better able to get an understanding of their workers and culture. In accordance with the popular belief, the results of this study show that Bahamian respondents are highly focused on their relationships, while maintaining a moderately high score on the task orientation. Managers and expatriates can certainly count on Bahamian employees and colleagues to develop a good relationship with vendors, suppliers and customers. 


\section{AUTHOR INFORMATION}

Bahaudin G. Mujtaba, D.B.A., is an Associate Professor of Management and Human Resources at Nova Southeastern University. Bahaudin was given the prestigious annual "Faculty of the Year Award" for the 2005 Academic Year at NSU's H. Wayne Huizenga School of Business and Entrepreneurship. Bahaudin has served as manager, trainer, and management development specialist in the corporate world as well as a director, department chair and faculty member in academia. His areas of research are ethics, leadership, training, and diversity management. Bahaudin can be reached through email at: mujtaba@nova.edu.

\section{REFERENCES}

1. Cavico, F. J. \& Mujtaba, B. G. (2008). Legal Challenges for the Global Manager and Entrepreneur. Kendal Hunt Publishing Company. United States.

2. Hofstede, G. (1983). National cultures in four dimensions: a research-based theory of cultural differences among nations. International Studies of Management and Organization, 13, 46-74.

3. Hofstede, G. (1993). Cultural constraints in management theories. The Executive, 7, 81-94.

4. Huang, K.Y. \& Mujtaba, B. G. (2009). Stress, task, and relationship orientations of Taiwanese adults: an examination of gender in this high-context culture. Journal of International Business and Cultural Studies, $3,1-12$.

5. Kaifi, B.A., \& Mujtaba, B.G. (2009). Workforce discrimination: An inquiry on the perspectives of AfghanAmerican Professionals. Journal of Business Studies Quarterly, 1(1), 1-15.

6. Kaifi, B.A., and Mujtaba, B. G. (2010). Transformational leadership and the impact of socialization in the Afghan culture: a study of behavioral differences based on gender, age, and place of birth. International Leadership Journal, 2(2), 33-52.

7. Karadjova-Stoev, G. \& Mujtaba, B. G. (2009). Strategic human resource management and global expansion lessons from the Euro Disney challenges in France. International Business and Economics Research Journal, 8(1), 69-78.

8. Kaweevisultrakul, T., Mujtaba, B. G., and Puriveth, P. (2009). Leadership and Managerial Implications of Healthcare Employees' Knowledge Sharing Intentions: A Study of Respondents in the Pharmaceutical Industry of Thailand. International Leadership Journal, 3(3/4), 04-34.

9. Mujtaba, B. G. (2007). Cross Cultural Management and Negotiation Practices. ILEAD Academy Publications; Florida, United States. ISBN: 978-0-9774211-2-1.

10. Mujtaba, B. G. \& Balboa, A. (2009). Comparing Filipino and American Task and Relationship Orientations. Journal of Applied Management and Entrepreneurship. 14(2). 82-98.

11. Mujtaba. B.G. \& McCartney. T. (2010). Managing Workplace Stress and Conflict amid Change (2 $2^{\text {nd }}$ edition). ILEAD Academy, Davie, Florida.

12. Northouse, P. G. (2010). Leadership: theory and practice. $5^{\text {th }}$ edition. SAGE Publications. Thousand Oaks, London.

13. Tajaddini, R. \& Mujtaba, B. G. (2009). Stress Perceptions and Leadership Orientation of Malaysians: Exploring their Similarities and Differences with Americans. Chinese Business Review, 8(8), 26-42.

14. Trompenaars, F. (1993). Riding the Waves of Culture Understanding Diversity in Global Business. New York: Irwin.

15. Walters Balfour, C. C., and Mujtaba, B. G. (2009). Are Male Employees Promoted More Often Than Females Who Are Just As Qualified? Journal of Diversity Management, 4(2), 7-18. 


\section{NOTES}

